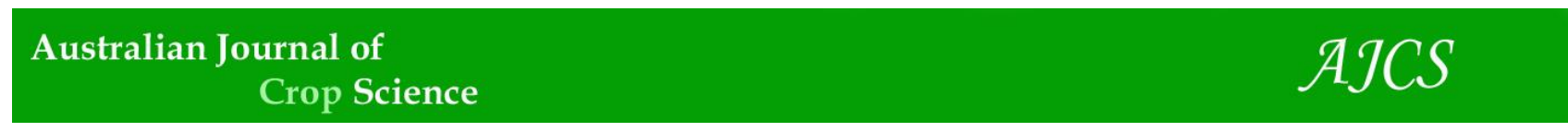

AJCS 12(05):778-787 (2018)

ISSN:1835-2707

doi: $10.21475 /$ ajcs.18.12.05.PNE925

\title{
Production of kiwi snack slice with different thickness: Drying kinetics, sensory and physicochemical analysis
}

\author{
Inacia dos Santos Moreira, Wilton Pereira da Silva ${ }^{*}$, Deise Souza de Castro, Luzia Márcia de Melo Silva, \\ Josivanda Palmeira Gomes and Cleide Maria D. P. S. e Silva
}

Federal University of Campina Grande, Campus I, PB, Brazil

*Corresponding author: wiltonps@uol.com.br

Abstract

In the modern world, light and healthy meals are increasingly consumed between the main meal courses. Therefore, market has made a wide variety of products of this type available, usually without artificial additives. This study aimed to produce snacks through the thin-layer drying of kiwi slices. Circular kiwi slices were cut into various thicknesses (5.0, 10.0 and $15.0 \mathrm{~mm})$ and subject to different drying air temperatures $\left(50,60,70\right.$ and $\left.80^{\circ} \mathrm{C}\right)$. Drying was described using several mathematical models, both diffusion (boundary condition of the third kind) and empirical (Henderson-Pabis, Lewis, Page, Silva et al.) models. According to diffusion model, kiwi slices showed an almost uniform moisture distribution over time. The Page equation/model showed the best fit to the experimental data, compared to other models. At the end of the drying process (until equilibrium), slices with initial thickness of $5.0 \mathrm{~mm}$ had a rigid consistency, suitable for production of flour through grinding. On the other hand, slices with initial thicknesses of 10.0 and $15.0 \mathrm{~mm}$ were soft; thus, they can be consumed as snacks. Sensory and physicochemical analyses showed that the product cut with initial thickness of $15.0 \mathrm{~mm}$ and dried at temperature of 70 o C (until moisture content of $0.31 \mathrm{~kg}$ water $/ \mathrm{kg}_{\text {dry matter }}$ ) was the tastiest one and showed good results for the analyzed chemical compounds.

Keywords: Actinidia deliciosa, food preservation, mathematical models, dried kiwi, sensory and physicochemical analyses. Abbreviations: $A_{w_{-}}$water activity, SS/TA_soluble solids and titratable acidity.

\section{Introduction}

Kiwi (Actinidia deliciosa) is a fruit originated from the mountainous regions of South China. According to Deng et al. (2014), kiwi has significant effects on human health, such as antiviral activity, protection against oxidative damages to DNA, and anticancer activity, being widely used by pharmaceutical and food industries. Among the various existing species, Actinidia deliciosa stands out for having a balance between acidity and the amount of sugars. In the last years, its production was one those that most increased in the global market, due to various important factors such as easy sale of the product in the market, profitable prices and easy cultivation. According to the data published by FAOSTAT (2015), the largest global producers of kiwi in 2013 were China Mainland (1.8 million ton), Italy (0.45 million ton), New Zealand ( 0.38 million ton) and Chile ( 0.26 million ton).

Kiwi is consumed as fresh fruits and also used in the elaboration of products such as jellies, juices, jams and beverages, among others. The limitation to its consumption is associated with the short shelf life, due to the large amount of water in its fruits, which facilitates the rapid biochemical and microbiological transformations of the fresh product. Thus, kiwi drying is one of the alternatives for commercialization and it can also improve some of characteristics, since the water activity of the product are decreased during the drying process, reducing the reactions of degradation (Doymaz and Pala, 2003; Simal et al., 2005). Drying is one of the methods that is mostly used by the agroindustry to prolong the lifetime of biological products and ensure their quality. According to Dehghannya et al. (2016), convective drying using hot air is still the most popular method applied to remove water from fruits and vegetables. However, according to some researchers (Kaya et al., 2008; Demiray and Tulek, 2016), many of the properties of agricultural products are affected by drying conditions. Thus, studies on drying modeling of products become necessary, not only involving aspects of mass and heat transfer, but also aiming to minimize possible quality losses.

Dried kiwi slices, show a smooth consistency. They can be consumed as a snack, because they are tasty and nutritious. Thus, description of drying of circular kiwi slices, cut in a certain thickness, contributes to the industrialization of snacks that can be obtained from this fruits. The correct boundary condition of the process must be identified, if drying is described by a diffusion model. Simal et al. (2005) described drying of circular kiwi slices, with initial moisture content close to $5.0 \mathrm{~kg}_{\text {water }} / \mathrm{kg}_{\text {dry matter, }}$ with thickness of 6.0 $\mathrm{mm}$, at the temperatures of 35 and $65{ }^{\circ} \mathrm{C}$. In the description of the process, the authors used a diffusion model with boundary condition of the first kind, which means that the Biot number referring to the mass transfer is assumed to be infinite. However, Chen et al. (2001) used an opposite idea 
with respect to the Biot number. Chen et al. (2001) argued that it is reasonable to assume a uniform moisture distribution inside the kiwi slices during drying. Naturally, this assumption means to admit that the Biot number for the mass transport is sufficiently small (lower than 0.1), which guarantees the uniform moisture distribution inside the slices, at any time. On the other hand, the application of reliable mathematical models allows predicting the correct behavior of the various phenomena that occur during the drying process, leading to the reduction of the operational cost (Dionello et al., 2009). Among available models for the description of a drying process, there are many on diffusion basis (Nguyen and Price, 2007; Silva et al., 2013; Da Silva et al., 2015). Their advantage, besides the description of the drying kinetics, is to predict moisture distribution at any time. The empirical basis models (Diamante et al., 2010; Kaleta and Gornicki, 2010; Silva et al., 2013 and 2014), can only describe the kinetics of the process. In this context, the objectives of this study are defined as follows:

This study aimed to conduct experiments of thin-layer drying of circular kiwi slices. The slices were cut in different thicknesses and placed in a forced-air oven at various temperatures. Another objective was to identify the correct boundary condition of diffusion model used to describe the process. Besides diffusion model, four empirical equations with up to two fit parameters were also used to describe the drying kinetics, through nonlinear regression. Lastly, a sensory analysis of the dried slices under various experimental conditions was conducted, and also the physicochemical analysis of the fresh product and of the dry product best evaluated by the tasters.

\section{Results and discussion}

\section{Drying experiments}

The initial moisture content of the kiwi fruits was 6.11

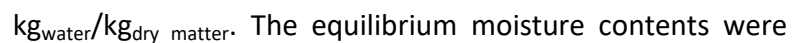
determined at the end of each drying for the description of the kinetics, with the means values of $0.18,0.16,0.13$ and $0.10 \mathrm{~kg}_{\text {water }} / \mathrm{kg}_{\text {dry matter }}$ for the temperatures of $50,60,70$ and $80{ }^{\circ} \mathrm{C}$, respectively. The temperature and relative air humidity in the environment were 25.8 으 and $83.67 \%$, respectively.

Figure 1 shows the experimental data referring to drying of kiwi slices with initial thicknesses of 5.0, 10.0 and $15.0 \mathrm{~mm}$ on a same axis system for each of the drying air temperatures $\left(50,60,70\right.$ and $\left.80^{\circ} \mathrm{C}\right)$.

For a given temperature (Figure 1), the fastest drying was occurred for kiwi slices with the smallest initial thickness (5.0 $\mathrm{mm}$ ), while the slowest one occurred for slices with the largest initial thickness $(15.0 \mathrm{~mm})$, as expected. On the other hand, for a certain thickness, the higher the air temperature, the shorter the drying time, i.e., the higher the drying rate. Similar experimental results were found in the literature, such as Nguyen and Price (2007), who studied drying of bananas sliced in thicknesses of 10 and $20 \mathrm{~mm}$ at temperatures of 50,60 and $70^{\circ} \mathrm{C}$.

At the end of the drying processes (until the equilibrium), slices with thickness of $5.0 \mathrm{~mm}$ showed a rigid consistency, while slices with initial thicknesses of 10.0 and $15.0 \mathrm{~mm}$ were soft, at all drying temperatures.
It should be noted that the drying kinetics of a product depends on various factors such as hot air speed, initial moisture content, final moisture content, relative humidity, temperature, dimensions, form, composition, external surface, intermittence, pressure and porosity, among others. Hence, it is frequently simpler to define models with a few parameters that represent, in one way or another, all the factors that influence the process. Therefore, the results referring to models proposed in this study are presented hereinafter.

\section{Description of diffusion model}

In the case of a diffusion model, most factors that influence the drying process are encompassed by the convective mass transfer coefficient (external surface), $h$, and by the effective mass diffusivity (internal medium), $D$. These two process parameters, along with a characteristic dimension of the product (thickness, in the case of infinite slab) can be combined to express one single parameter, called mass transfer Biot number Equation (4), for the case of an infinite slab. The results obtained for the description of drying of kiwi slices through diffusion model with boundary condition of the third kind are presented in Table 2, with emphasis on the effective mass diffusivity (high values) and mass transfer Biot number (low values).

The graphs referring to the description of the drying kinetics through diffusion model proposed in this study are shown in Figure 2. According to the results of Table 2 and also the graphs of Figure 2, the best fits occurred for the temperature of 50 ㅇ. However, in general, all results for the description of the drying kinetics can be considered only reasonable. On the other hand, observing Table 2 for a certain temperature, the effective mass diffusivity increases with the thickness and, for a given thickness, this parameter increases with the temperature. Regarding Table 2, it must be noted that all values obtained for the mass transfer Biot number is on the order of $10^{-3}$. The interpretation of this result is very interesting, whereas inside a kiwi slice the moisture distribution at a certain time is virtually uniform, which means moisture is lost by the slices without generating considerable moisture gradients. In order to visualize this information, the unidimensional domain (thickness) was divided into 100 parts, and the $x$ coordinate of the central point of each part was substituted with Equation (6), which allowed determining the moisture contents of each one of these 100 parts along the $x$ direction (thickness). Moisture distribution was analyzed for all experiments, but this study only presents the results for drying of slices with initial thickness of $10.0 \mathrm{~mm}$ at $70{ }^{\circ} \mathrm{C}$, at the times of 100,150 and $200 \mathrm{~min}$. These results can be visualized in Figure 3.

For drying processes with moisture distribution similar to Figure 3, various researchers disregarded diffusion model, substituting it for simpler models such as Reaction Engineering Approach (REA) (Chen et al., 2001; Putrano et al., 2011; Putranto and Chen, 2016; Gao et al., 2016; Haque et al., 2016), or even an empirical equation (Diamante et al., 2010; Kaleta and Gornicki, 2010; Silva et al., 2013 and 2014). This occurs because, according to Figure 3 , there are no significant moisture gradients inside the slices, at a given time. Interestingly, Chen et al. (2001) argued that it would be reasonable to assume almost uniform distribution (found 
Table 1. Empirical models used to predict drying of kiwi slices.

\begin{tabular}{lll}
\hline Models & Empirical equation & Reference \\
\hline Henderson-Pabis & $X^{*}(t)=a \cdot \exp (-b . t)$ & Diamante et al. (2010) \\
Lewis & $X^{*}(t)=\exp (-b . t)$ & Kaleta and Gornicki (2010) \\
Page & $X^{*}(t)=\exp \left(-a \cdot t^{b}\right)$ & Silva et al. (2008) \\
Silva et alii & $X^{*}(t)=\exp (-a . t-b \sqrt{t})$ & Silva et al. (2013) \\
\hline
\end{tabular}

$\mathrm{a}$ and $\mathrm{b}$ : parameters of the models.
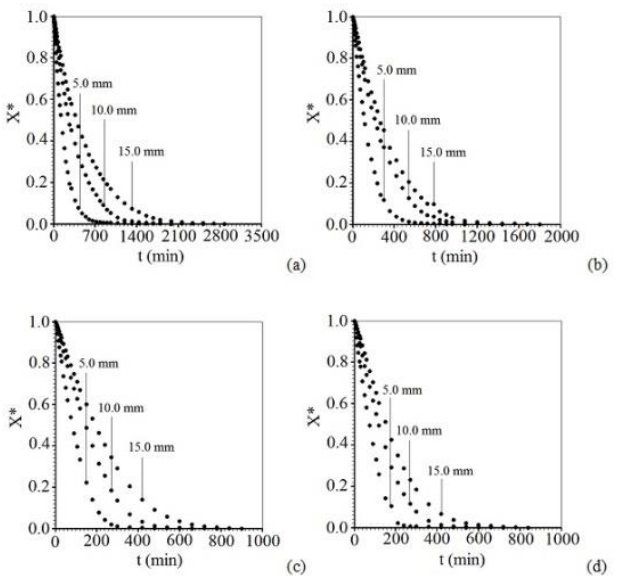

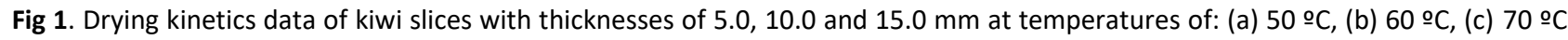

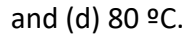

Table 2. Effective mass diffusivity, Biot number, determination coefficient $\left(R^{2}\right)$ and chi-square $\left(\chi^{2}\right)$ obtained in the description of drying of kiwi slices with initial thicknesses of 5.0, 10.0 and $15.0 \mathrm{~mm}$ at temperatures of $50,60,70$ and $80{ }^{\circ} \mathrm{C}$, using the diffusion model.

\begin{tabular}{|c|c|c|c|c|c|}
\hline$T\left({ }^{\circ} \mathrm{C}\right)$ & $L(\mathrm{~mm})$ & $D\left(\mathrm{~m}^{2} \min ^{-1}\right)$ & $\mathrm{Bi} \times 10^{3}$ & $R^{2}$ & $\chi^{2} \times 10^{3}$ \\
\hline \multirow{4}{*}{$50 \stackrel{\circ}{C}$} & 5.0 & $2.12 \times 10^{-5}$ & 1.75 & 0.9993 & 3.672 \\
\hline & 10.0 & $4.08 \times 10^{-5}$ & 1.75 & 0.9994 & 4.372 \\
\hline & 15.0 & $10.3 \times 10^{-5}$ & 1.00 & 0.9998 & 3.228 \\
\hline & 5.0 & $2.89 \times 10^{-5}$ & 1.50 & 0.9987 & 6.696 \\
\hline \multirow[t]{3}{*}{$60 \stackrel{\circ}{\circ}$} & 10.0 & $7.36 \times 10^{-5}$ & 1.25 & 0.9979 & 13.13 \\
\hline & 15.0 & $13.5 \times 10^{-5}$ & 1.25 & 0.9981 & 12.61 \\
\hline & 5.0 & $4.17 \times 10^{-5}$ & 1.50 & 0.9954 & 23.69 \\
\hline \multirow[t]{3}{*}{$70 \stackrel{\circ}{ }=$} & 10.0 & $9.64 \times 10^{-5}$ & 1.50 & 0.9938 & 37.70 \\
\hline & 15.0 & $16.1 \times 10^{-5}$ & 1.50 & 0.9952 & 28.31 \\
\hline & 5.0 & $4.79 \times 10^{-5}$ & 1.50 & 0.9935 & 28.08 \\
\hline \multirow[t]{2}{*}{$80 \stackrel{\circ}{C}$} & 10.0 & $11.6 \times 10^{-5}$ & 1.50 & 0.9945 & 30.94 \\
\hline & 15.0 & $19.9 \times 10^{-5}$ & 1.50 & 0.9954 & 29.94 \\
\hline
\end{tabular}
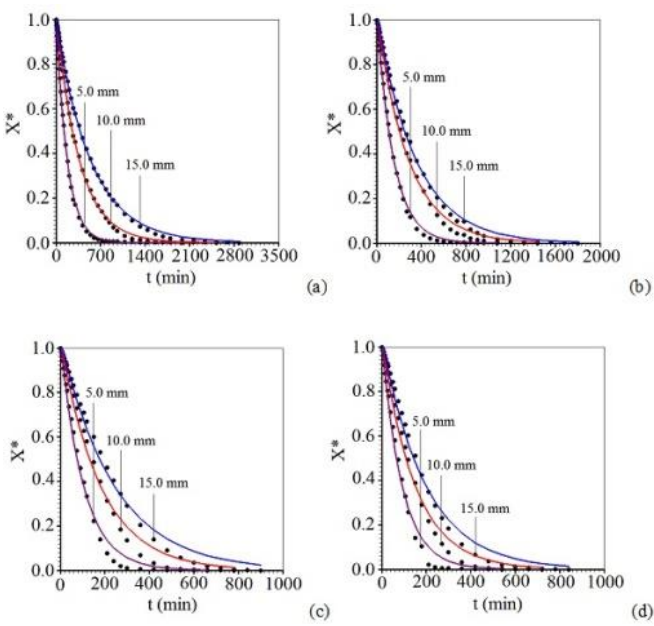

Fig 2. Description through diffusion model of the drying kinetics of kiwi slices with initial thicknesses of 5.0 (purple), 10.0 (red) and

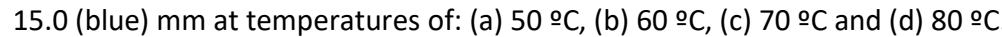


Table 3. Fit parameters, determination coefficients $\left(R^{2}\right)$ and chi-squares $\left(\chi^{2}\right)$ for the models of Henderson-Pabis and Lewis, in the description of drying of kiwi slices with initial thicknesses of 5.0, 10.0 and $15.0 \mathrm{~mm}$, for the different temperatures.

\begin{tabular}{|c|c|c|c|c|c|}
\hline \multirow[t]{2}{*}{$T\left({ }^{\circ} \mathrm{C}\right)$} & \multirow[t]{2}{*}{$L(\mathrm{~mm})$} & \multicolumn{2}{|c|}{ Parameters } & \multirow[t]{2}{*}{$R^{2}$} & \multirow[t]{2}{*}{$x^{2}$} \\
\hline & & a & b & & \\
\hline & & \multicolumn{2}{|c|}{ Henderson-Pabis } & & \\
\hline & 5.0 & 1.0203 & 0.0058 & 0.9993 & 0.0041 \\
\hline \multirow[t]{3}{*}{$50 \stackrel{\circ}{C}$} & 10.0 & 1.0148 & 0.0027 & 0.9995 & 0.0035 \\
\hline & 15.0 & 1.0087 & 0.0019 & 0.9997 & 0.0024 \\
\hline & 5.0 & 1.0380 & 0.0067 & 0.9984 & 0.0084 \\
\hline \multirow[t]{3}{*}{$60 \stackrel{\circ}{C}$} & 10.0 & 1.0319 & 0.0035 & 0.9978 & 0.0142 \\
\hline & 15.0 & 1.0317 & 0.0029 & 0.9980 & 0.0136 \\
\hline & 5.0 & 1.0553 & 0.0099 & 0.9941 & 0.0251 \\
\hline \multirow[t]{3}{*}{$70 \stackrel{\circ}{\circ}$} & 10.0 & 1.0588 & 0.0057 & 0.9922 & 0.0384 \\
\hline & 15.0 & 1.0463 & 0.0042 & 0.9943 & 0.0303 \\
\hline & 5.0 & 1.0493 & 0.0112 & 0.9922 & 0.0299 \\
\hline \multirow[t]{4}{*}{$80 \stackrel{\circ}{C}$} & 10.0 & 1.0584 & 0.0069 & 0.9930 & 0.0318 \\
\hline & 15.0 & 1.0592 & 0.0053 & 0.9940 & 0.0305 \\
\hline & & Lewis & & & \\
\hline & 5.0 & - & 0.0056 & 0.9993 & 0.0066 \\
\hline \multirow[t]{3}{*}{$50 \stackrel{\circ}{ } \mathrm{C}$} & 10.0 & - & 0.0027 & 0.9996 & 0.0055 \\
\hline & 15.0 & - & 0.0018 & 0.9998 & 0.0032 \\
\hline & 5.0 & - & 0.0063 & 0.9985 & 0.0165 \\
\hline \multirow[t]{3}{*}{$60 \stackrel{\circ}{C}$} & 10.0 & - & 0.0034 & 0.9984 & 0.0224 \\
\hline & 15.0 & - & 0.0028 & 0.9985 & 0.0227 \\
\hline & 5.0 & - & 0.0092 & 0.9949 & 0.0389 \\
\hline \multirow[t]{3}{*}{$70 \stackrel{\circ}{C}$} & 10.0 & - & 0.0053 & 0.9940 & 0.0602 \\
\hline & 15.0 & - & 0.0039 & 0.9961 & 0.0463 \\
\hline & 5.0 & - & 0.0105 & 0.9934 & 0.0400 \\
\hline \multirow[t]{2}{*}{$80 \stackrel{\circ}{ } \mathrm{C}$} & 10.0 & - & 0.0064 & 0.9944 & 0.0510 \\
\hline & 15.0 & - & 0.0048 & 0.9954 & 0.0536 \\
\hline
\end{tabular}

Table 4. Fit parameters, determination coefficients $\left(R^{2}\right)$ and chi-squares $\left(\chi^{2}\right)$ of models of Page and Silva et alii, in the description of drying of kiwi slices with initial thicknesses of 5.0,10.0 and $15.0 \mathrm{~mm}$, for the different temperatures.

\begin{tabular}{|c|c|c|c|c|c|}
\hline \multirow[t]{2}{*}{$T\left({ }^{\circ} \mathrm{C}\right)$} & \multirow[t]{2}{*}{$L(\mathrm{~mm})$} & \multicolumn{2}{|c|}{ Parameters } & \multirow[t]{2}{*}{$R^{2}$} & \multirow[t]{2}{*}{$x^{2}$} \\
\hline & & $a$ & $\mathrm{~b}$ & & \\
\hline & & & Page & & \\
\hline & 5 & 0.0035 & 1.0921 & 0.9999 & 0.0004 \\
\hline \multirow[t]{3}{*}{$50 \stackrel{\circ}{C}$} & 10 & 0.0019 & 1.0631 & 0.9998 & 0.0014 \\
\hline & 15 & 0.0015 & 1.0377 & 0.9998 & 0.0016 \\
\hline & 5 & 0.0029 & 1.1564 & 0.9999 & 0.0004 \\
\hline \multirow[t]{3}{*}{$60 \stackrel{\circ}{C}$} & 10 & 0.0014 & 1.1550 & 0.9996 & 0.0022 \\
\hline & 15 & 0.0011 & 1.1552 & 0.9998 & 0.0012 \\
\hline & 5 & 0.0028 & 1.2610 & 0.9991 & 0.0035 \\
\hline \multirow[t]{3}{*}{$70 \stackrel{\circ}{C}$} & 10 & 0.0010 & 1.3150 & 0.9992 & 0.0039 \\
\hline & 15 & 0.0010 & 1.2508 & 0.9993 & 0.0034 \\
\hline & 5 & 0.0033 & 1.2588 & 0.9981 & 0.0072 \\
\hline \multirow[t]{2}{*}{$80 \stackrel{\circ}{C}$} & 10 & 0.0015 & 1.2996 & 0.9995 & 0.0021 \\
\hline & 15 & 0.0010 & 1.2998 & 0.9999 & 0.0005 \\
\hline \multicolumn{6}{|c|}{ Silva et alii } \\
\hline \multirow{3}{*}{$50 \stackrel{\circ}{C}$} & 5 & 0.0063 & -0.0086 & 0.9997 & 0.0016 \\
\hline & 10 & 0.0030 & -0.0042 & 0.9997 & 0.0020 \\
\hline & 15 & 0.0019 & -0.0020 & 0.9997 & 0.0019 \\
\hline \multirow{3}{*}{$60 \stackrel{\circ}{C}$} & 5 & 0.0077 & -0.0156 & 0.9995 & 0.0026 \\
\hline & 10 & 0.0041 & -0.0104 & 0.9989 & 0.0069 \\
\hline & 15 & 0.0033 & -0.0096 & 0.9992 & 0.0055 \\
\hline & 5 & 0.0122 & -0.0280 & 0.9971 & 0.0121 \\
\hline \multirow[t]{3}{*}{$70 \stackrel{\circ}{C}$} & 10 & 0.0072 & -0.0234 & 0.9962 & 0.0183 \\
\hline & 15 & 0.0051 & -0.0164 & 0.9971 & 0.0149 \\
\hline & 5 & 0.0137 & -0.0282 & 0.9952 & 0.0178 \\
\hline \multirow[t]{2}{*}{$80 \stackrel{\circ}{C}$} & 10 & 0.0087 & -0.0253 & 0.9969 & 0.0141 \\
\hline & 15 & 0.0066 & -0.0224 & 0.9978 & 0.0110 \\
\hline
\end{tabular}


Table 5. Physicochemical characterization of kiwi, fresh and dried at temperature of $70 \stackrel{\circ}{ } \mathrm{C}$, with initial thickness of $15.0 \mathrm{~mm}$.

\begin{tabular}{|c|c|c|c|c|}
\hline Analyzed parameters & Fresh kiwi & & Dried kiwi & \\
\hline Moisture content (\%, w.b.) & 85.9 & \pm 3.4 & 23.6 & \pm 0.9 \\
\hline Water activity, $A_{w}$ & 0.980 & \pm 0.020 & 0.475 & \pm 0.012 \\
\hline Total soluble solids (ㅇrix) & 12.60 & \pm 0.19 & 51.6 & \pm 1.0 \\
\hline Total titratable acidity (\% of citric acid) & 1.04 & \pm 0.06 & 1.34 & \pm 0.05 \\
\hline $\mathrm{pH}$ & 3.24 & \pm 0.03 & 3.00 & \pm 0.03 \\
\hline Soluble Solids/Total Acidity ratio & 12.18 & \pm 0.20 & 38.53 & \pm 0.33 \\
\hline Vitamin C (mg/100g $\left.g_{\text {sample }}\right)$ & 81.0 & \pm 0.9 & 67.8 & \pm 0.7 \\
\hline Phenolic compounds ( $\left.\mathrm{mg} / 100 \mathrm{~g}_{\text {sample }}\right)$ & 121.9 & \pm 1.8 & 251.4 & \pm 3.2 \\
\hline Flavonoids (mg/100g $\mathrm{g}_{\text {sample }}$ ) & 2.88 & \pm 0.06 & 2.88 & \pm 0.06 \\
\hline Total chlorophylls (mg/100g $\left.\mathrm{g}_{\text {sample }}\right)$ & 2.22 & \pm 0.07 & 1.19 & \pm 0.04 \\
\hline Total carotenoids (mg/100g $\left.\mathrm{g}_{\text {sample }}\right)$ & 0.45 & \pm 0.06 & 1.11 & \pm 0.07 \\
\hline Luminosity (L) & 40.7 & \pm 0.4 & 39.8 & \pm 0.4 \\
\hline Intensity of red $\left(+a^{*}\right)$ & -4.07 & \pm 0.05 & 8.65 & \pm 0.17 \\
\hline Intensity of yellow $\left(+b^{*}\right)$ & 19.8 & \pm 0.6 & 29.6 & \pm 0.8 \\
\hline
\end{tabular}
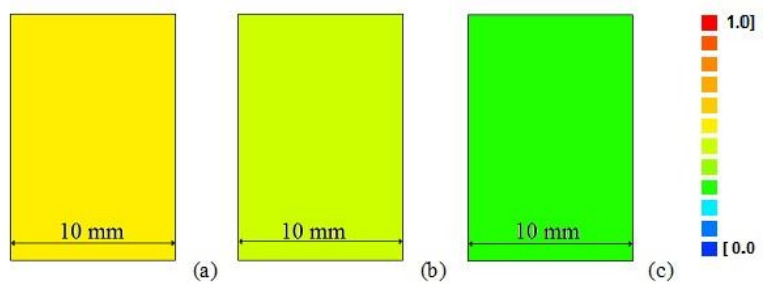

Fig 3. Moisture distribution in the infinite slab for drying at $70^{\circ} \mathrm{C}$ in kiwi slices with initial thickness of $10.0 \mathrm{~mm}$ at the times of: (a) $100 \mathrm{~min}$, (b) $150 \mathrm{~min}$ and (c) $200 \mathrm{~min}$.
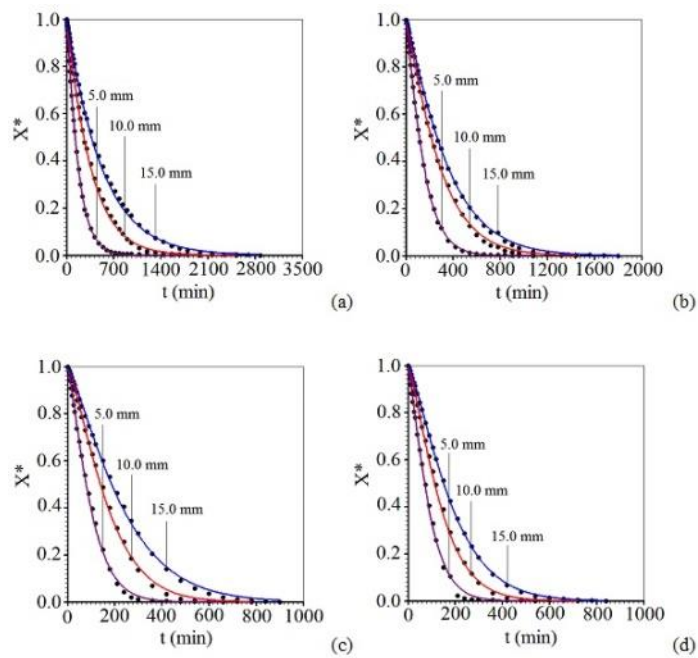

Fig 4. Description through the Page model of the drying kinetics of kiwi slices with initial thicknesses of 5.0 (purple), 10.0 (red) and

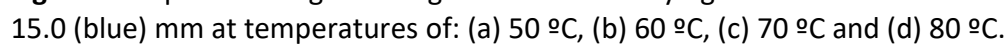

in the present study, through proposed diffusion model), to use their drying model (REA, Reaction Engineering Approach) applied to the description of drying of kiwi slices. On the other hand, comparing problem of drying with heat transfer, there is a certain similarity with the Newton's Law of Cooling, also considered as a case of lumped model ( $\mathrm{Su}$, 2001). With these considerations, one of the main advantages of a diffusion model, which is possibility of determination of the moisture content distribution inside the kiwi slices at a given time (with the consequent possibility of calculation of the internal stresses that can produce irregular deformations) is not so useful for description of this type of drying. In spite of that, diffusion model is important, for allowing the definition of the correct boundary condition of the problem and the prediction of the absence of significant moisture gradients inside the product. However, in this case, a simpler model may be more efficient to describe the drying kinetics. Therefore, it should be pointed out that, according to Silva et al. (2012), for such a low Biot number, the infinite series that represents the solution of the diffusion equation can be represented only by its first term, with negligible truncation error. In this case, this first term can be interpreted as the Henderson-Pabis equation, e.g. referenced by Diamante et al. (2010). On the other hand, since the moisture content was written in the dimensionless form, one should expect the Henderson-Pabis equation to describe the drying kinetics in a similar way to the equation of Lewis, referenced by Kaleta and Gornicki (2010). It is worth mentioning that this latter equation (Lewis) is analogous to the equation of Newton for cooling. 
Considering the statistical indicators presented in Table 2 and the graphs of Figure 2, and also observing the results obtained for the Biot number in all drying processes, as well as the previous discussion referring to its implications, this study suggests incapability of diffusion model, but only for the objective of describing the thin-layer drying kinetics of kiwi slices. Therefore, the empirical model may describe the drying kinetics better.

\section{Description of empirical models}

Table 3 shows the parameters obtained from the fits of models of Henderson-Pabis and Lewis to the experimental data of drying kinetics of kiwi slices with initial thicknesses of 5.0, 10.0 and $15.0 \mathrm{~mm}$. This table also shows the determination of coefficient $\left(R^{2}\right)$ and chi-square $\left(\chi^{2}\right)$ obtained for drying at temperatures of $50,60,70$ and $80 \stackrel{\circ}{\circ}$. In general, the statistical indicators obtained with the Lewis model were slightly inferior to those obtained with Henderson-Pabis model; and both are slightly inferior to diffusion model with respect to these statistical indicators. However, the last three results confirm that, for obtaining a low mass transfer Biot number in a drying process, diffusion model with boundary condition of the third kind is almost equivalent to Henderson-Pabis model (and also Lewis model).

It should be noted that, for the models of Henderson-Pabis and Lewis, the drying rate $\left(-\mathrm{d} X^{*} / \mathrm{d} t\right)$ is proportional to the moisture ratio $\left(X^{*}\right)$, and the constant of proportionality is the parameter $b$ of these models. The results obtained in Table 3 for both previously mentioned models allowed claiming that, for a certain thickness of kiwi slices, the increase of temperature causes increment in the drying rate under a certain moisture ratio and, consequently, an increment in the parameter $b$. In addition, for a certain temperature, the parameter $b$ decreased with the increase in thickness, indicating that the drying rate decreases for a certain moisture ratio, which is an expected result. Similar results have been reported in the literature, such as those of Leite et al. (2015), who fitted mathematical models to the drying kinetics data of banana slices.

Table 4 shows the parameters obtained from the fit of models of Page and Silva et al. (2013) to the experimental data of drying kinetics, and also the statistical indicators determination coefficient $\left(R^{2}\right)$ and chi-square $\left(\chi^{2}\right)$.

Models of Page (1949) and Silva et al. (2013) showed superior statistical indicators in relation to the other models mentioned above. However, Page model, with $R^{2}$ ranging from 0.9981 to 0.9999 , was superior to model of Silva et al. (2013). The Page model was selected to represent the drying kinetics shown in the graphs of Figure 4.

The results obtained from Page model were similar to those reported by Simal et al. (2005) on the drying kinetics of kiwi in the form of cubes, in a temperature range of 30 to 90 ㄷ. On the other hand, likewise the present study, Silva et al. (2014), compared the mathematical models to describe the thin-layer drying kinetics of whole bananas, and found that models of Page and Silva et al. (2013) were the best ones to describe the experimental data.

\section{Physicochemical analysis of fresh and dried kiwi}

A preliminary study on the sensory analysis indicated that the kiwi slices with initial thickness of $15.0 \mathrm{~mm}$, dried at the temperature of $70 \stackrel{\circ}{ } \mathrm{C}$, until the moisture content of 0.31 $\mathrm{kg}_{\text {water }} / \mathrm{kg}_{\text {dry matter }}$ is reached, are the tastiest ones. For these conditions, the product maintained some of its organoleptic characteristics closer to those of the fresh kiwi, compared to slices dried at other conditions, accentuating some properties such as the bitter-sweet taste. Thus, besides the physicochemical analysis of the fresh product, the dried product was also subjected to physicochemical analysis under the previously mentioned conditions.

The moisture content of the fresh kiwi was $85.9 \%$ (wet basis, w.b.), and this result was close to that reported by Çalışkan et al. (2015), who determined $81.2 \%$. The results for the determination of water activity of fresh and dried kiwi are presented in Table 5. The result obtained for dried kiwi (0.475) indicates that this product is less vulnerable to microbiological degradation. As is known, the reduction in water activity to a little less than 0.6 is sufficient to suppress the growth of pathogenic agents, including some strains of osmophilic yeasts that can still grow at values of up to 0.6 (Gava et al., 2008, Medeiros et al., 2016). Therefore, drying of kiwi slices for the production of snacks was effective in the reduction of water activity to a safe value.

The content of total soluble solids of the dried kiwi slices was 51.6 oBrix. This amount is approximately equivalent to four times the value determined for the fresh fruit (12.6 oBrix). Such increment in total soluble solids is associated with the removal of water, which promotes the concentration of solutes. The content of total soluble solids for fresh kiwi reported by Benítez et al. (2013) is very close to that obtained in the present study. They studied the aloe vera-based edible coating on minimally processed kiwi fruits, and found a oBrix value equal to 12.7 .

After the kiwi slices are dried, there is an increase in total titratable acidity, from $1.04 \%$ to $1.34 \%$ of citric acid. This increase can also be attributed to the concentration of acids present in the product due to the water removal. On the other hand, the results of Table 5 show that the drying process can cause a decrease in the $\mathrm{pH}$ of the dried kiwi slices. However, slices of fresh and dried kiwi showed the $\mathrm{pH}$ lower than 3.50, implying that fruits are acidic, contributing to its preservation by restriction of the microorganisms' growth, especially bacteria.

For the ratio between soluble solids and titratable acidity (SS/TA), dried kiwi slices showed approximately three times the ratio obtained for the fresh fruit, evidencing that water removal significantly contributed to the value on this order.

The Kiwi, compared with other fruits, is an excellent source of vitamin $\mathrm{C}$. The content of vitamin $\mathrm{C}$ in fresh kiwi fruit was $(81.0 \pm 0.9) \mathrm{mg} / 100 \mathrm{~g}_{\text {sample. The drying process }}$ influenced the content of vitamin $C$, which was equal to $(67.8 \pm 0.7) \mathrm{mg} / 100 \mathrm{~g}_{\text {sample, }}$, for slices with initial thickness of $15.0 \mathrm{~mm}$, dried at 70 oC until moisture content of 0.31 $\mathrm{kg}_{\text {water }} / \mathrm{kg}_{\text {dry matter, }}$ as presented in Table 5 . This significant loss of vitamin $C$ during the manufacturing of the product was similar to those reported by Çalışkan et al (2015), during drying of kiwi.

According to Table 5, the results revealed an increase in the content of total phenolic compounds of the final product in the fresh kiwi. Again, the increase in the content of phenolic compounds with the drying process is justified by the loss of water with a consequent increase in the concentration of most chemical compounds in the kiwi fruits during drying. On the other hand, the results for total flavonoids showed equal values of $2.88 \mathrm{mg} / 100 \mathrm{~g}_{\text {sample }}$ in the fresh and dried fruit. 
The drying process to obtain the kiwi snacks contributed to the reduction of total chlorophyll content and; therefore, influenced the difference of color in fresh fruits. Consequently, there was a slight increase in the concentration of total carotenoids, causing greater yellow color in the dried kiwi, as observed in color data parameters of Table 5. As it is known, the color of the surface of the food is the first quality parameter evaluated by the consumers and it is fundamental for the acceptance of product, even before it is tasted (López et al, 2013). The luminosity (L) of the fresh kiwi (40.7) was close to that of dried kiwi (39.8). Similar results for the $L$ values were reported by Ramallo and Mascheroni (2012) during drying of pineapple slices. These authors observed that the parameter $L$ was not significantly affected by drying.

The values of $a^{*}$ and $b^{*}$ increased for the dried product, compared to the fresh fruits. For parameter $a^{*}$, which varies from red $\left(+a^{*}\right)$ to green $\left(-a^{*}\right)$, the dried kiwi exhibited color closer to red. Regarding the parameter $b^{*}$, which indicates the tones from yellow $\left(+b^{*}\right)$ to blue $\left(-b^{*}\right)$, its increase was influenced by the drying process, demonstrating a tendency to yellow for the dried kiwi sample, compared with the fresh sample. This is a tendency observed for other fruit drying processes, as reported in the study of Ramallo and Mascheroni (2012) during drying of pineapple at temperatures of 45 and 60 ㅇ. For the dried product, there was a predominance of the intensity of yellow in relation to the intensity of red, indicating that drying process has an important influence on the final color of the dehydrated product. The increase of these parameters ( $a^{*}$ and $b^{*}$ ) during drying can be attributed to the concentration of the fruit constituents (chlorophylls and carotenoids, among others). Results similar to those obtained in the present study for the values of $a^{*}$ and $b^{*}$ have been reported by various researchers, such as Silva et al. (2016).

\section{Materials and methods}

\section{Conduction of experiments}

The study was carried out at the Laboratory of Storage and Processing of Agricultural Products (LAPPA) of the Academic Unit of Agricultural Engineering (UAEA) of the Federal University of Campina Grande (UFCG), using approximately $20 \mathrm{~kg}$ of kiwi, cultivar Hayward, obtained from the State Supply Center (EMPASA-CEASA of Campina Grande, Paraíba, Brazil) in the stage of commercial maturation. The fruits were transported to the laboratory, where they were washed in a solution containing $1 \%$ neutral detergent and, after rinsed in running water, immersed in a solution of $15 \%$ sodium hypochlorite for 5 minutes. After drying the wet skin of the fruits in the open air, they were peeled off using stainless-steel knives and were cut into the circular slices with $\sim 49.0 \mathrm{~mm}$ of diameter, with thicknesses of 5.0, 10.0 and $15.0 \mathrm{~mm}$.

Thin-layer drying of the circular slices was performed in a forced-air oven (Marconi ${ }^{\circ}$, model MA 035/3IN250) operating at temperatures of $50,60,70$ and 80 ․C. Drying temperatures were selected based on the commonly used ranges for agricultural products. The tests were conducted in triplicate; the moisture content was determined by the gravimetric method and the slices were weighed on an analytical scale, until reaching the equilibrium moisture content.
Before each drying process, kiwi samples were collected for the determination of the initial moisture content, using the standard method of the oven at 105 oC for $24 \mathrm{~h}$, to obtain the dry matter. The initial moisture content was determined through the arithmetic mean of twelve different determinations. To describe the drying kinetics, the moisture contents were determined in regular time intervals, until the equilibrium.

The drying curves were obtained after converting the original data of the moisture content on a dry basis, $X(t)$, to the corresponding parameter in the dimensionless form (moisture ratio), $X^{*}(t)$, according to Equation (1):

$$
X^{*}(t)=\frac{X(t)-X_{e q}}{X_{0}-X_{e q}}
$$

Where; $X^{*}(t)$ and $X(t)$ are calculated over time, $X_{e q}$ is the equilibrium moisture content and $X_{0}$ is the initial moisture content, both on a dry basis.

In order to obtain the snacks (dried kiwi), the drying processes were also interrupted before the equilibrium, with various final moisture contents, considering as the best final moisture content selected by the sensory analysis.

\section{Mathematical models for drying}

The experimental values for the moisture ratio over time were determined for each slice thickness and drying air temperature were predicted by a diffusion model, with boundary condition of the third kind, and by four empirical models.

\section{Diffusion model}

For the definition of diffusion model, some preliminary assumptions were made: (1) the initial moisture distribution inside the product is uniform; (2) diffusion is the main mechanism of mass transport inside the product, and shrinkage can be disregarded; (3) kiwi slices are considered homogeneous and isotropic; (4) the convective mass transfer coefficient and effective mass diffusivity do not vary along drying; and (5) drying is considered under isothermal conditions. In addition, since the diameter of the slices (about $49.0 \mathrm{~mm}$ ) is much larger than the thicknesses previously established in the experiments, the geometry considered for the product was an infinite slab. Thus, for the boundary condition of the third kind, the analytical solution of the diffusion equation is given by the series shown in Equation (2) (Luikov, 1968), in which only the first " $n t$ " terms of the infinite series were used:

$$
X^{*}(t)=\sum_{n=1}^{n t} B_{n} \exp \left(-\mu_{n}^{2} \frac{D}{(L / 2)^{2}} t\right)
$$

Where; $L$ is the thickness of the infinite slab; $D$ is the effective mass diffusivity and $t$ is the drying time. The $B_{n}$ coefficients are given by:

$$
B_{n}=\frac{2 B i^{2}}{\mu_{n}^{2}\left(B i^{2}+B i+\mu_{n}^{2}\right)}
$$

Where; $B i$ is the mass transfer Biot number, given by

$$
B i=\frac{h(L / 2)}{D}
$$

and the parameter $h$ is the convective mass transfer coefficient. In the last equations, $\mu_{n}$ are the roots of the following transcendental equation: 


$$
\cot \mu=\frac{\mu}{B i}
$$

which is called characteristic equation for the infinite slab. It must be observed that the use of the boundary condition of the third kind aims at calculating the mass transfer Biot number relative to drying, without the need to stipulate it previously. Thus, it is possible to verify whether the most adequate choice is to consider a low Biot number, as done by Chen et al. (2001), or a value tending to infinite (boundary condition of the first kind), as previously established by Simal et al. (2005). It should be pointed out that Chen et al. (2001) and Simal et al. (2005) described similar thin-layer drying of kiwi slices, using hot air.

Equation (2) was fitted to the experimental data through the optimization methodology proposed by Silva et al. (2010), using Convective Adsorption-Desorption Software. It should be noted that the highest truncation error of the infinite series given by Equation (2) occurs for $t=0$, and this error depends on the Biot number referring to drying (Silva et al., 2012). In order to define the number of terms ( $n t)$ to be used in Equation (2), the study of Silva et al. (2012) was taken into consideration. These researchers observed that, for $B i=0.001$, only 1 term is necessary to obtain $X^{*}(0)=1.0$, which is the expected value. On the other hand, when the Biot number increased, the truncation error was also significantly increased. For instance, $B i=200$, considering only the first term of the series resulted in $X^{*}(0)=0.5405$, with an error of approximately $46 \%$. Thus, it is necessary to significantly increase the number of terms of the series to obtain negligible, or at least acceptable, truncation errors. In the present study, the number of terms previously established for the series was $n t=16$, which allows to identify the correct boundary condition, through the determined Biot number.

Once the process parameters for diffusion model were determined, the moisture distribution at a given time $t$ can be determined by the solution of the diffusion equation dependent on the position $x$, with the origin established in the center of the thickness of the slices:

$$
X^{*}(x, t)=\sum_{n=1}^{n t} A_{n} \cos \left(\frac{\mu_{n}}{L / 2} x\right) \exp \left[-\frac{\mu_{n}^{2}}{(L / 2)^{2}} D t\right]
$$

With

$$
A_{n}=\frac{4 \sin \mu_{n}}{2 \mu_{n}+\sin \left(2 \mu_{n}\right)}
$$

\section{Empirical models}

Four empirical equations a maximum of two fit parameters were selected as observed in Table 1 . The empirical equations were fitted to the experimental data using the computational program LAB Fit Curve Fitting Software (Silva et al., 2004). The criteria used to determine the best fit of all mathematical models to the experimental data were the determination of coefficient $\left(R^{2}\right)$ and the chi-square $\left(\chi^{2}\right)$.

\section{Physicochemical analyses of fresh and dried kiwi}

Sensory analysis was conducted using dried kiwi slices obtained under various experimental conditions, involving ten tasters, to define the ideal conditions for the production of the snacks. The fresh and dried kiwi best evaluated by the tasters was subjected to physicochemical analysis, performed in triplicate, as detailed below.
Water activity $\left(A_{w}\right)$ was determined using the instrument Aqualab 3TE (Decagon), with a sample at ambient temperature (approximately $25 \mathrm{o} C$ ). The content of soluble solids ( ${ }^{\circ}$ Brix) was determined through the reading of the refraction index in a benchtop $A B B E$ refractometer (model Q767B), according to the recommendation proposed by AOAC (2005). The total titratable acidity (TA, \% of citric acid) was determined through titration with standardized solution of sodium hydroxide $(0.1 \mathrm{~N} \mathrm{NaOH})$, using $1 \%$ alcoholic phenolphthalein as indicator. The results were expressed in percentage of citric acid (IAL, 2008).

The $\mathrm{pH}$ was determined in a digital potentiometer, using buffer solutions with $\mathrm{pH} 4.0$ and 7.0 for calibration, according to IAL (2008). The SS/TA ratio was determined by the relationship between soluble solids and titratable acidity. The amount of vitamin $\mathrm{C}$ was determined using $1.0 \mathrm{~g}$ of the sample diluted in $49.0 \mathrm{~mL}$ of oxalic acid. Titration was performed using the Tillman's solution, according to the methodology described by IAL (2008). Total phenolic compounds were determined using the Folin-Ciocalteu method described by Waterhouse (2006). Total flavonoids were determined according to the colorimetric method with aluminum chloride, according to the methodology of Woisky and Salatino (1998). Total chlorophyll and total carotenoids were determined according to Lichtenthaler (1987). It should be pointed out that the contents of vitamin C, total phenolic compounds, total flavonoids, total chlorophyll and total carotenoids were expressed in milligrams of the compound per $100 \mathrm{~g}$ of the sample $\left(\mathrm{mg} / 100 \mathrm{~g}_{\text {sample }}\right)$.

The color parameters were determined using a spectrophotometer (Mini Scan Hunter Lab XE Plus), in the CieLab color system, obtaining the following parameters: $L^{*}$ - luminosity; $a^{*}$ - transition from green $\left(-a^{*}\right)$ to red $\left(+a^{*}\right)$; and $b^{*}$ - transition from blue $\left(-b^{*}\right)$ to yellow $\left(+b^{*}\right)$.

\section{Conclusion}

According to the obtained results, the initial thickness of the kiwi slices and the drying temperature influenced the water loss. The higher the temperature and the smaller the thickness, the drying time would be shorter. Through diffusion model, it was possible to conclude that the moisture distribution was virtually uniform inside the slices during drying and; therefore, the boundary condition of the first kind is completely inadequate to describe the process. On the other hand, the mathematical model that fitted best to the drying kinetics data of kiwi slices was the Page equation, with determination coefficients higher than 0.9981 and chi-squares lower than 0.0072 . The results of the sensory analysis indicated that the kiwi slices with initial thickness of $15.0 \mathrm{~mm}$, dried at the temperature of $70 \mathrm{oC}$ until the moisture content of $0.31 \mathrm{~kg}_{\text {water }} / \mathrm{kg}_{\text {dry matter, }}$ were the tastiest ones. For these conditions, the product maintained some of its organoleptic characteristics close to those of the fresh fruit, accentuating some of these properties, such as the bitter-sweet taste, but with a significant loss of vitamin C. Additionally, kiwi drying had an important influence on the final color of the dehydrated product and on other physical and chemical properties.

\section{Acknowledgment}

The second author would like to thank CNPq (Conselho Nacional de Desenvolvimento Científico e Tecnológico) for 
the support given to this research and for his research grant (Processes Number 302480/2015-3 and 444053/2014-0).

\section{References}

AOAC (Association of Official Analytical Chemists). 2005. Official Methods of Analysis of the Association of Official Analytical Chemists. 18 ed., Gaithersburg/ Maryland.

Benítez S, Achaerandio I, Sepulcre F, Pujolà M (2013) Aloe vera based edible coatings improve the quality of minimally processed 'Hayward' kiwifruit. Post Biol Techn. 81: 29-36.

Chen XD, Pirini W, Ozilgen, M (2001) The reaction engineering approach to modelling drying of thin layer of pulped Kiwifruit flesh under conditions of small Biot numbers. Chem Eng Process. 40:311-320.

Çalışkan G, Ergün K, Dirim SN (2015) Freeze Drying of Kiwi (Actinidia deliciosa) Puree and the Powder Properties. Ital J Food Sci. 27:385-396.

Da Silva WP, Silva CMDPS, Silva Junior AF, Queiroz AJM (2015) A numerical approach to determine some properties of cylindrical pieces of bananas during drying. Int J Food Eng.11:335-347.

Dehghannya J, Gorbani R, Ghanbarzadeh B (2016) Shrinkage of Mirabelle Plum during Hot Air Drying as Influenced by Ultrasound-Assisted Osmotic Dehydration. Int J Food Prop. 19:1093-1103.

Demiray E, Tulek Y (2016) Degradation Kinetics of $\beta$ Carotene in Carrot Slices during Convective Drying. Int J Food Prop. DOI:10.1080/10942912.2016.1147460

Deng J, Sun T, Cao W, Fan D, Cheng N, Wang B, Gao H, Yang $H$ (2014) Extraction optimization and functional properties of proteins from kiwi fruit (actinidia chinensis planch.) seeds. IntJ Food Prop. 17: 1612-1625.

Diamante LM, Ihns R, Savage GP, Vanhanen L (2010) A new mathematical model for thin layer drying of fruits. Int $J$ Food Sci Technol. 45: 1956-1962.

Dionello RG, Berbert PA, Molina MAB, Pereira RC, Viana AP, Carlesso VO (2009). Assessment of convective drying models for fresh and osmo-dehydrated pineapple rings. Cienc Tecnol Aliment. 29:232-240.

Doymaz I, Pala M (2003) The thin-layer drying characteristics of corn. J Food Eng, 60:125-130.

FAOSTAT (Food and Agriculture Organization of the United Nations). 2015. Available at: <http://faostat3.fao.org/download/Q/QC/E>. Access at: July 26, 2016.

Gao X, Wang J, Wang S, Li Z (2016) Modelling of Drying Kinetics of Green Peas by Reaction Engineering Approach. Dry Technol, 34:437-442.

Gava AJ, Silva CAB, Frias JRG (2008) Food Technology: Principles and applications. São Paulo, Publishing company: Nobel, 2008. 512 p.

Haque MA, Adhikari B, Putranto A (2016) Predictions of drying kinetics of aqueous droplets containing WPI-lactose and WPI-trehalose by application of composite reaction engineering approach (REA). J Food Eng. 189:29-36.

IAL (Instituto Adolfo Lutz). 2008. Normas Analíticas do Instituto Adolfo Lutz: Métodos Químicos e Físicos para Análise de Alimentos. 4th. ed., São Paulo: IAL, 1020p.

Kaleta A, Górnicki K (2010) Evaluation of drying models of apple (var. McIntosh) dried in a convective dryer. IntJ Food Sci Technol. 45:891-898.

Kaya A, Aydin O, Dincer I (2008) Experimental and numerical investigation of heat and mass transfer during drying of
Hayward kiwi fruits (Actinidia Deliciosa Planch). J Food Eng. 88: 323-330.

Leite ALMP, Silva FS, Porto AG, Piasson D, Santos P (2015) Contração volumétrica e cinética de secagem de fatias de banana variedade Terra. Pesq Agro Trop. 45:155-162.

López J, Vega-Gálvez A, Torres MJ, Lemus-Mondaca R, Quispe-Fuentes I, Scala KD (2013) Effect of dehydration temperature on physico-chemical properties and antioxidant capacity of goldenberry (Physalis peruviana L.). Chi J Agric Res. 73: 293-300.

Lichtenthaler HK (1987) Chlorophylls and carotenoids: pigments of photosynthetic biomembranes. Meth Enzymol. 148:350-382.

Luikov AV (1968) Analytical heat diffusion theory, Academic Press, Inc. Ltd, London.

Medeiros RAB, Barros ZMP, Carvalho CBO, Neta EGF, Maciel MIS, Azoubel PM (2016) Influence of dual-stage sugar substitution pretreatment on drying kinetics and quality parameters of mango. LWT - Food Sci Technol 67:167-173.

Nguyen MH, Price WE (2007) Air-drying of banana: Influence of experimental parameters, slab thickness, banana maturity and harvesting season. J Food Eng. 79: 200-207.

Page, C. Factors influencing the maximum rates of air drying shelled corn in thin layers. (1949). MS Thesis - Purdue University, West Lafayette, 1949.Putranto A, Chen XD, Devahastin S, Xiao Z, Webley PA (2011) Application of the reaction engineering approach (REA) for modeling intermittent drying under time-varying humidity and temperature. Chem Eng Sci. 66: 2149-2156.

Putranto A, Chen XD (2016) Drying of a system of multiple solvents: Modeling by the reaction engineering approach. AIChE Journal. 62: 2144-2153.

Ramallo LA, Mascheroni RH (2012) Quality evaluation of pineapple fruit during drying process. Food bioprod proces, 90:275-283.

Silva WP, Silva CMDPS, Cavalcanti CGB, Silva DPS, Soares IB, Oliveira JAS, Silva CDPS (2004) LAB Fit Curve Fitting: A software in Portuguese for treatment of experimental data. Rev Bras Ens Fis. 26: 419-427.

Silva WP, Mata MERMC, Silva CDPS, Guedes MA, Lima AGB (2008) Determination of diffusivity and activation energy for cowpea grains (Vigna unguiculata (L.) Walp.), alwaysgreen variety, based on its drying behavior. Eng Agríc. 28:325-333.

Silva WP, Precker JW, Silva CMDPS, Gomes JP (2010) Determination of effective diffusivity and convective mass transfer coefficient for cylindrical solids via analytical solution and inverse method: application to the drying of rough rice. J Food Eng 98:302-308.

Silva WP, Farias VSO, Neves GA, Lima AGB (2012) Modeling of water transport in roof tiles by removal of moisture at isothermal conditions. Heat Mass Transf. 48: 809-821.

Silva WP, Silva CMDPS, Sousa JAR, Farias VSO (2013) Empirical and diffusion models to describe water transport into chickpea (Cicer arietinum L.). Int J.Food Sci Technol. 48:267-273.

Silva WP, Silva CMDPS, Gama FJA, Gomes JP (2014) Mathematical models to describe thin-layer drying and to determine drying rate of whole bananas. J Saudi Soc Agric Sci. 3:67-74.

Silva GD, Barros ZMP, Medeiros RAB, Carvalho CBO, Brandão SCR, Azoubel, PM (2016) Pretreatments for melon drying implementing ultrasound and vacuum. LWT - Food Sci Technol. 74:114-119. 
Simal S, Femenia A, Garau MC, Rosselló C (2005) Use of exponential, Page's and diffusional models to simulate the drying kinetics of kiwi fruit. J Food Eng, 66:323-328.

Su Jian (2001) Improved lumped models for asymmetric cooling of a long slab by heat convection. Int Com Heat Mass Transf. 28:973-983.
Waterhouse A (2006) Folin-ciocalteau micro method for total phenol in wine. American Journal of Enology and Viticulture, 3-5.

Woisky RG, Salatino A (1998) Analysis of própolis: some parameters and procedures for chemical quality control. J Apicult Res. 37:99-105. 